\title{
Migration of rice planthoppers and their vectored re-emerging and novel rice viruses in East Asia
}

\author{
Akira Otuka* \\ Kyushu Okinawa Agricultural Research Center, National Agriculture and Food Research Organization, Kumamoto, Japan
}

\section{Edited by:}

II-Ryong Choi, International Rice

Research Institute, Philippines

\section{Reviewed by:}

II-Ryong Choi, International Rice Research Institute, Philippines Guohui Zhou, College of Natural Resources and Environment, South China Agricultural University, China

\section{${ }^{*}$ Correspondence:}

Akira Otuka, Kyushu Okinawa Agricultural Research Center, National Agriculture and Food Research Organization, 2421 Suya, Koshi, Kumamoto 8611192, Japan e-mail: aotuka@affrc.go.jp
This review examines recent studies of the migration of three rice planthoppers, Laodelphax striatellus, Sogatella furcifera, and Nilaparvata lugens, in East Asia. Laodelphax striatellus has recently broken out in Jiangsu province, eastern China. The population density in the province started to increase in the early 2000s and peaked in 2004. In 2005, Rice stripe virus (RSV) viruliferous rate of $L$. striatellus peaked at $31.3 \%$. Since then, rice stripe disease spread severely across the whole province. Due to the migration of the RSV vectors, the rice stripe disease spread to neighboring countries Japan and Korea. An overseas migration of L. striatellus that occurred in 2008 was analyzed, when a slow-moving cold vortex, a type of low pressure system, reached western Japan from Jiangsu, carrying the insects into Japan. Subsequently the rice stripe diseases struck these areas in Japan severely. In Korea, similar situations occurred in 2009, 2011, and 2012. Their migration sources were also estimated to be in Jiangsu by backward trajectory analysis. Rice black-streaked dwarf virus, whose vector is L. striatellus, has recently re-emerged in eastern China, and the evidence for overseas migrations of the virus, just like the RSV's migrations, has been given. A method of predicting the overseas migration of $L$. striatellus has been developed by Japanese, Chinese, and Korean institutes. An evaluation of the prediction showed that this method properly predicted migration events that occurred in East Asia from 2008 to 2011. Southern rice black-streaked dwarf virus (SRBSDV) was first found in Guangdong province. Its vector is S. furcifera. An outbreak of SRBSDV occurred in southern China in 2009 and spread to Vietnam the same year. This disease and virus were also found in Japan in 2010. The epidemic triggered many migration studies to investigate concrete spring-summer migration routes in China, and the addition of migration sources for early arrivals in Guangdong and Guangxi have been proposed. Nilaparvata lugens is also an important insect pest of rice. Its migration situations on the Indochina peninsula and return migrations in China are discussed.

Keywords: rice planthoppers, migration, trajectory analysis, entomological radar, virus disease

\section{INTRODUCTION}

Some viruses in economic plants spread as they are carried by their invertebrate vectors (Matthews, 1991), and sometimes even migrate overseas. Rice planthoppers, major rice pests, and their vectored rice viruses are examples. Rice planthoppers consist of three species: the small brown planthopper, Laodelphax striatellus (Fallén); the white-backed planthopper, Sogatella furcifera (Horváth), and the brown planthopper, Nilaparvata lugens (Stål; Hemiptera: Delphacidae). Currently, rice planthoppers have been causing various problems in East Asia. An outbreak of N. lugens occurred in China, Korea, and Japan in 2005 (Cheng and Zhu, 2006). Major reasons for the outbreak included favorable weather conditions and insecticide resistance of the vector (Cheng and Zhu, 2006; Matsumura et al., 2008). N. lugens and its rice viral diseases also severely damaged rice in southern Vietnam in 2006-2007, and the Vietnamese government temporarily stopped the country's rice exports, which affected the world rice market (Chien et al., 2007). S. furcifera has caused a novel virus disease in southern China since the early 2000s, and the disease later spread to wide paddy areas in China, northern to central Vietnam, and Japan (Zhou et al., 2010;
Hoang et al., 2011; Matsumura and Sakai, 2011). The density of $L$. striatellus in eastern China rapidly increased in the mid 2000s, and an outbreak of rice strip disease occurred (Zhou, 2010). Rice strip disease has spread to Japan and Korea from 2008 to the present (Otuka et al., 2010; Lee et al., 2012). Meanwhile, local plant protection institutes in each country conducted intensive surveys and took effective control measures against the vectors and diseases (Zhou, 2010).

Recent outbreaks of rice planthoppers and related virus diseases that occurred in East Asia were closely related to the vectors' migration. This review, therefore, examines the recent development of migration studies of rice planthoppers in East Asia, and presents a vivid image of the dispersion of viruses vectored by the insects. The review consists of three parts, covering the migration of $L$. striatellus, the migration of tropical rice planthoppers $S$. furcifera and N. lugens, and a discussion.

\section{Laodelphax striatellus}

This species is widely distributed in East Asia, including Japan, Korea, and China, and transmits Rice stripe virus (RSV) to rice 


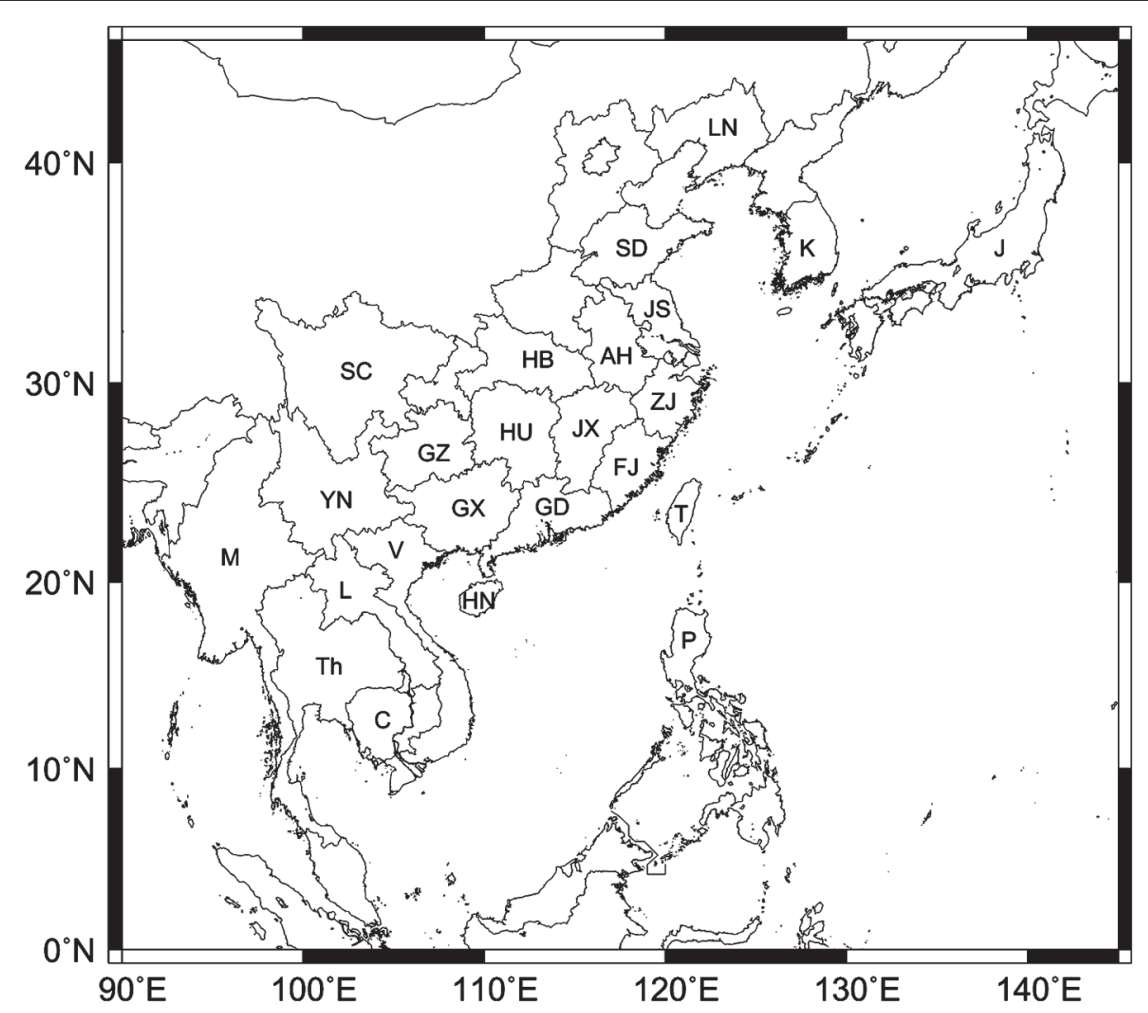

FIGURE 1 | Locations of Chinese provinces and East Asian countries of interest. Abbreviations LN, SD, JS, AH, ZJ, HB, JX, FJ, HU, GD, GZ, GX, HN $S C, T, P, V, C, L, T h, M, K$, and J indicate Liaoning, Shandong, Jiangsu, Anhui,
Zhejiang, Hubei, Jiangxi, Fujian, Hunan, Guangdong, Guizhou, Guangxi, Hainan, Sichuan, Taiwan, the Philippines, Vietnam, Cambodia, Laos, Thailand, Myanmar, South Korea, and Japan, respectively. plants in persistent and transovarial manners (Falk and Tsai, 1998). Since L. striatellus is able to overwinter at mid-latitudes, including all areas in Japan, outbreaks of rice stripe disease in Japan had been mostly believed to be caused by domestic populations until 2008, when there was an overseas mass migration of L. striatellus in early June in western Japan followed by an outbreak of rice stripe disease (Otuka et al., 2010). The migration source was thought to be Jiangsu province, eastern China (Figure 1; Otuka et al., 2010). A set of events related to the migration, therefore, had started in China.

\section{RECENT SITUATION IN EASTERN CHINA}

The rice-wheat or -barley double-cropping system is used in Jiangsu. Indica hybrid rice was introduced there in the late 1970s in order to increase rice yield, and by the mid-1980s the area of hybrid rice accounted for a third of the total rice area (Gu et al., 2005; Sogawa, 2005). Since L. striatellus cannot effectively multiply on hybrid rice compared with japonica rice (Liu et al., 2007), rice stripe disease was not a problem until the end of the 1990s (Sogawa, 2005). In the late 1990s, the ratio of japonica rice started to increase in the province, because japonica varieties of good taste were more profitable in the market than indica hybrid rice varieties (Gu et al., 2005); by 2002 the area of japonica rice exceeded $80 \%$ of the total (Sogawa, 2005). However, major japonica varieties used in Jiangsu, e.g., Wuyujing 3 and Wuyunjing 7, were susceptible to both L. striatellus and RSV (Yang et al., 2002; $\mathrm{Gu}$ et al., 2005). The prevalence of susceptible varieties was the first factor for the outbreak of the insect. Secondly, early rice seeding and early transplanting became popular especially in the middle and northern parts of the province, in order to obtain high and stable yields, making the best use of high temperatures in summer (Yang et al., 2002). This resulted in the overlap of wheat harvesting and rice seedling, making it much easier for the host transfer of L. striatellus long-winged adults (Yang et al., 2002). Thirdly, the practice of direct seeding of wheat and barley without plowing after rice harvesting spread in Jiangsu in order to reduce labor. In these fields, the insects transferred easily from rice to wheat or barley (Yang et al., 2002). These three major factors helped the insects rapidly multiply in Jiangsu (Sogawa, 2005). The viruliferous rate of the first generation in Jiangsu peaked at 31.3\% in 2005 (Zhou, 2010). Rice stripe disease consequently spread across the entire province. The occurrence area of this disease in paddy fields peaked at 1.57 million ha (79\% of the total paddy area) in Jiangsu in 2004 (Zhou, 2010). The use of chemicals to control viruliferous vector insects has been one of the main measures used. An insecticide, imidacloprid or a Chinese product named bichonglin, was recommended to spray (Gu et al., 2005; Xi et al., 2005; Xian et al., 2005), but it was applied on average at least five times in a single summer crop (Zhou, 2010). These intensive uses resulted in the development of resistance against the insecticide (Ma et al., 2007; Otuka et al., 2010; Sanada-Morimura et al., 2011).

L. striatellus and rice stripe disease in Jiangsu have been managed as follows. One of the main methods of controlling rice 
stripe disease was to introduce rice cultivars resistant to the virus (Iizuka, 1989; Zhou, 2010). When an epidemic of rice stripe disease occurred in the 1980s in the Kanto district of eastern Japan, cultivars resistant to the virus were introduced and the epidemic quickly ceased (Iizuka, 1989), indicating the effectiveness of resistance cultivars. Other methods to control the disease included chemical control of the vectors, introduction of a gap between wheat and rice cultivations (Kiritani, 1983; Wang et al., 2008; Zhou, 2010), covering of rice seedlings with an insect-proof mesh, and plowing before the seeding of wheat and barley in autumn (Zhou, 2010; Zhu, 2012). All the measures taken in Jiangsu are a standard way to control the pest, and the importance of them has been re-recognized there. With these integrated measures, the RSV viruliferous rate in Jiangsu has decreased to a low level of 3\% in 2012 (Zhu, 2012).

\section{OVERSEAS MASS MIGRATION OF L. steriatellus}

The 2008 overseas mass migration of L. steriatellus occurred in western Japan under these circumstances in China. Large catches of L. steriatellus adults by a net trap (63 insects) or a suction trap (106) were recorded on June 5, 2008, simultaneously at two different sites $100 \mathrm{~km}$ apart on Kyushu Island (Otuka et al., 2010). In order to allocate the possible source of the migration, a backward trajectory analysis that traced air parcels backward from points over the trap sites was conducted, and the trajectories reached Jiangsu in about 24-36 h, suggesting Jiangsu may have been the source (Otuka et al., 2010). Immigrants were collected from rice fields in immigrated areas in Japan within 2-4 days after the migration. Insects in Jiangsu province were also collected at the end of September to early October 2008. These insects' resistance to insecticides was tested, and both the immigrants and the Jiangsu population showed resistance against imidacloprid with high $\mathrm{LD}_{50}$ values in the topical application method, whereas Japanese domestic populations collected in Kyushu before the 2008 migration event showed susceptibility to the same insecticide (Otuka et al., 2010). In addition, the RSV viruliferous rates of the immigrant populations were reported to be higher (9.2$11.5 \%)$ than those of the domestic populations $(2.9-4.0 \%)$ by enzyme-linked immunosorbent assays (Nakagawa and Mizobe, 2010; Otuka et al., 2010), indicating supportive evidence for the overseas migration.

An outbreak of rice stripe disease subsequently occurred on the western coast of the Kyushu and Chugoku districts (Ohtsu et al., 2009; Otuka et al., 2010; Nakagawa and Mizobe, 2010). The total occurrence area of rice stripe disease in Nagasaki prefecture in 2008 was 10,720 ha, which was a $126 \%$ increase over the previous year (MAFF, 2009). All these analytical results suggested that $L$. steriatellus migrated from Jiangsu to western Japan and caused the outbreak of rice stripe disease.

\section{IN KOREA}

Responding to the mass migration to Japan, Korean scientists quickly set up a monitoring network of 13 net traps $(10 \mathrm{~m}$ high above the ground) for L. striatellus along their western coast in May 2009. A similar mass immigration occurred from May 30 to June 1, 2009 (Choi et al., 2010; Otuka et al., 2012a). The catch numbers at Sinan and Taean, located along the western coast of the Korean peninsula, were 819 and 963, respectively, about 10 times larger than those in the previous Japanese case. Based on the backward trajectory analysis, a possible migration source for the Korean case was found to be Jiangsu (Otuka, 2009). The RSV viruliferous rate of L. striatellus was $5.3 \%$, and the occurrence area of rice stripe disease, located along the western coastal areas, was 21,500 ha in 2009 (Lee et al., 2012). Similar migration events occurred also in Taean, Gunsan, and Buan in 2011, and in Taean in 2012 (Jeong et al., 2012; Lee et al., 2012). According to surface weather maps for the times when these migration cases occurred, low-pressure systems over Bohai Sea in 2009 and 2011, and a high pressure system over the southern Yellow Sea in 2012, caused southwesterly winds that might have carried the insects to Korea.

\section{CHARACTERISTICS OF THE OVERSEAS MIGRATION}

The frequency of possible overseas migration of L. striatellus into the northern Kyushu district in relation to weather conditions was analyzed (Syobu et al., 2011). The investigation covered the 10year period from May 21, 2000, to June 10, 2009. One peak trap catch was recorded on May 27-28, 2006, and was associated with strong westerly winds at 850 and $925 \mathrm{hPa}$ levels to the south of a cold vortex that passed over the southern part of the Korean peninsula. The backward trajectory analysis suggested Jiangsu, China, as a possible migration source. Another case was the event in 2008 mentioned above. No immigration was found in Japan from 2010 to 2011 (Otuka et al., 2012a). Thus, in total two overseas migrations of L. striatellus may have occurred in 12 years in Japan.

On the other hand, three overseas migration events may have occurred in Korea form 2009 to 2012. In addition, Lee et al. (2012) reported that severe damage to rice by rice stripe disease occurred in western areas in 2001, 2007, and 2008, but it is not certain whether these damages were caused by local L. striatellus populations or overseas immigrants. However, a migration was predicted in 2008 by Figure 6a in Otuka et al. (2012a), and the predicted areas in southwestern Korea matched the damaged areas: Sinan, Jindo, Haenam, and Wando (Kim et al., 2009; Lee et al., 2012). Therefore, the 2008 case may be one of the overseas migrations. Thus, the frequency of a possible overseas migration in Korea would be four times in 5 years (2008 to 2012), which is higher than that in Japan. The difference in the event frequency is attributable to the location of the destination from the source. Korea is northeast of Jiangsu, whereas Japan is west of Jiangsu. In the middle latitudes, southwesterly winds blow frequently to the south of a low pressure system. The low-level jet stream over the East China Sea carrying various insects is a typical example (Seino et al., 1987). In contrast, sustaining westerly winds by a cold vortex seems less frequent (Syobu et al., 2011). Therefore, it can be said that Korea is unfortunately located in a migration-preferred direction from the source area.

The distance between the source and the destination might have affected the number of immigrants. The distance between western Japan and the coastal line of Jiangsu province is about $750 \mathrm{~km}$, whereas that between the Korean peninsula and Jiangsu is about $500 \mathrm{~km}$. The catch numbers in the net trap in Korea in 2009 were more than ten times larger than those in Japan. Moreover, the distribution of the immigrated areas in Japan and Korea is of interest. All estimated immigrated areas were confined to 
coastal regions (Ohtsu et al., 2009; Nakagawa and Mizobe, 2010; Lee et al., 2012). For example, in 2008 rice stripe disease occurred heavily in Nagasaki prefecture, located in the westernmost part of Kyushu Island, but no epidemic of the disease was reported in a neighboring prefecture, Saga (Ohtsu et al., 2009). In Yamaguchi prefecture, the outbreak of the disease happened mainly in the coastal areas (Nakagawa and Mizobe, 2010). Similarly, the disease's recent occurrence area in Korea was distributed along the western coastal line. These facts imply that $L$. striatellus invaded these areas by flying at low altitudes, because an outbreak of the disease could have occurred inland if the insects had flown at altitudes high enough to cross the mountains.

\section{DOMESTIC DISPERSION AND MIGRATION IN CHINA}

When the outbreak of $L$. striatellus and rice stripe disease spread to all of Jiangsu around 2004, the neighboring provinces of Zhejiang, Anhui, Shanghai, Shandong, and Hubei started to suffer similar problems (Wang et al., 2008). In Zhejiang province, the disease spread rapidly southward, from the northern to centraland eastern regions, with an increasing incidence each year from 2003 to 2006 (Wang et al., 2008). By 2006, the disease was severe in the northernmost parts of the province. The timing of the epidemic in Zhejiang province was just after the outbreak in Jiangsu. Increasing populations of RSV viruliferous vectors early in the season were clearly the primary source of the epidemic (Wang et al., 2008). Wang et al. (2008) did not discuss the source of the vectors. However, the situation in Zhejiang province and that in Jiangsu province suggest that the migration of viruliferous $L$. striatellus from Jiangsu could be, at least partly, the cause of the epidemic. More clearly, domestic migrations of the vectors were recently investigated in Zhejiang, Anhui, and Shandong provinces (Wan etal., 2011; Zhang et al., 2011; He et al., 2012). For example, a large immigration of L. striatellus in Jining, southern Shandong province, north of Jiangsu province, was observed by a light trap in the late night of 7 June, 2009, and backward trajectories suggested that a possible migration source was northern Jiangsu province (Zhang et al., 2011). They also studied forward trajectories for an emigration peak on 15 June, 2010, and the trajectories reached Liaoning province, suggesting a domestic overseas migration (Zhang et al., 2011). Similarly, possible migration from Jiangsu province to Liaoning province, a kind of overseas migration, has also been suggested (Zhou and Cheng, 2012).

\section{DIVERSITY OF RSV}

The vector migrates a long distance, and RSV does so as well. Therefore, the distribution of a viral population may be affected by the host's migration. The genetic diversity of the virus has been studied in East Asia (Wei et al., 2009; Jonson et al., 2009; Sakai et al., 2011). These studies included phylogenetic analyses of the nucleotide sequences of nucleocapsid protein $(\mathrm{N})$ and RNA3 intergenicregion (IR3) or the whole sequence of RNA3 of RSV isolates collected in Japan (collection years 2008 and 2009), eastern China (1997-2004), and western Korea (2007-2008). The results showed that RSV isolates in China were divided two types, labeled type I and II. The isolates from eastern China including Jiangsu consisted of type I, and those from Yunnan province, southern China, formed type II. Isolates from the Kyushu district of western
Japan and most of the isolates from western Korea belonged to type I. Additionally, isolates from the Kanto district, eastern Japan, and one isolate from Korea formed another subtype (J-K subtype in Sakai et al., 2011, or type II in Jonson et al., 2009). The distance between the Kyushu and Kanto districts is about 1,000 km, and the Kanto district is far from Jiangsu. These studies suggested that the RSV populations in the Kyushu district, Korea, and eastern China are indistinguishable from each other, and that the migration of L. striatellus from eastern China to Japan and Korea may have affected the structure of the RSV population in East Asia.

\section{RICE BLACK-STREAKED DWARF VIRUS}

Rice black-streaked dwarf disease caused by Rice black-streaked dwarf virus (genus Fujivirus; RBSDV) emerged in late japonica rice in Zhejiang province, eastern China in 1989, and expanded in the 1990s, having four major outbreaks in 1992, 1996, 1997 and 1998 (Wang et al., 2009). The epidemic of the disease on late japonica rice in Zhejiang province continued in the 2000s, and the total affected area increased from 26,000 ha in 2000 to 64,640 ha in 2005, spreading from eastern part to central and southern parts of the province (Wang et al., 2009). The virus has been detected in almost all the area of the province from 2008 to 2011 (Wu et al., 2013). As the density of the vector $L$. striatellus in Jiangsu province, a northern neighboring province of Zhejiang, increased in the 2000s as described above, the occurrence of rice black-streaked dwarf disease also increased from 20,500 ha in 2007 to 33,300 ha in 2009, and the paddy area of complete yield loss in the province reached to 2,000 ha in 2008 (Lan et al., 2012). When overseas mass migrations from Jiangsu province to South Korea possibly happened, the RBSDV viruliferous rate of $L$. striatellus caught in net traps along the western coast of the Korean peninsula in early June 2009 and 2011 were found to be 3.1 and 4.4 percent, respectively (Kim, 2009; Jeong et al., 2012), indicating that migrations of both RSV and RBSDV likely occurred due to the vectors' movement over the sea. No vector immigrant with co-infection of RSV and RBSDV in Korea has been found so far (Kim, 2009; Jeong et al., 2012). Since no resistant gene of rice for RBSDV has been found, vector control by chemicals in early susceptible stages of rice plants, and the use of an insect proof net for rice seedlings are major effective measures of disease control (Lan et al., 2012).

\section{PREDICTION OF MIGRATION OF L. striatellus}

A method has been developed to predict the overseas migration in East Asia (Otuka et al., 2012a). The source of the migration is assumed to be Jiangsu, China. The method consists of two steps: prediction of the emergence of the first generation of L. striatellus (the first step), and simulation of the migration route during a predicted emigration period (the second step; Otuka et al., 2012a).

The prediction of emergence is performed by calculating the daily increase in effective accumulative temperature (EAT) for L. striatellus starting from the first day of each year. The EAT is calculated with daily minimum and maximum temperatures in Dongtai, a city in central Jiangsu, and the data are obtained through the Internet in real time. Growth parameters of the insect for the EAT calculation, such as low-limit temperature and growthstop temperature, are those estimated for Japanese populations. The EAT value is updated daily, and a presumed increase is added 
until the predicted value exceeds a pre-defined threshold. The threshold for the emergence was previously determined by analyzing past migration events. The migration prediction period is 9 days, starting from the predicted emergence day - 3 days (prediction error), and ending on the emergence day +5 days (pre-emigration period of 2 days + prediction error). This is the prediction period.

Migration is then predicted during the prediction period (the second step). In the prediction model, insects take off at dusk and dawn then fly upward at a speed of $0.2 \mathrm{~m} / \mathrm{s}$ for an hour to make use of upper winds favorable to migration. There is no such observation for L. striatellus so far, but there is a radar observation of N. lugens flying upward in autumn in Jiangsu (Riley et al., 1991). During migration the insects move at the velocity of the wind, which is forecasted by a weather prediction model. The migration lasts $24 \mathrm{~h}$. The relative aerial density of the insects in the lowest calculation layer is calculated on the basis of the number of insects in each grid cell, and is drawn on a map. By this prediction, the areas and timing of immigration in Japan and Korea are presented. The prediction method was evaluated against the past migration events occurring in Japan and Korea, and the prediction had a 90\% accuracy rate (Otuka et al., 2012a). Now the method is implemented and operational in JPP-NET (http://www.jppnet.or.jp), database service provided by the Japan Plant Protection Association, Tokyo.

\section{Sogatella furcifera AND Nilaparvata lugens EPIDEMIC OF SRBSDV AND MIGRATION OF ITS VECTOR}

S. furcifera is a vector of SRBSDV that causes stunting, leaf darkening, and small enations on the stem and leaf back of rice plants (Zhou et al., 2008, 2013). This disease was first recognized in 2001 in Guangdong province, southern China, and in the next few years spread gradually to Guangxi, Hainan, Hunan, and Jiangxi provinces, but its infected hill ratio was low, $1 \%$ or less (Zhou et al., 2008,2010). In 2009, however, an epidemic of the disease occurred in Guangdong, Guangxi, Hainan, Hunan, Hubei, Jiangxi, Fujian, Zhejiang, and Anhui provinces; the total infected paddy area was about 400,000 ha, and a paddy area of 6,700 ha suffereda complete yield loss (Zhou etal., 2010; Zhao etal., 2011b). In the same year, an outbreak also occurred in Vietnam, where 19 central to northern provinces suffered from the disease (Hoang et al., 2011). In 2010, the infested area in China increased to more than 1.3 million ha in 13 provinces (Zhao et al., 2011b). In August 2010, the disease was first detected in forage rice in western Japan (Matsumura and Sakai, 2011). The virus was detected also across all of Zhejiang province by 2011 (Wu et al., 2013). The rapid spread of the virus throughout East Asia attracted scientists' renewed attention to the migration of the vector, S. furcifera.

\section{EARLY IMMIGRATION IN GUANGDONG AND GUANGXI}

Since Guangdong and Guangxi are possible sources of S. furcifera and $N$. lugens immigrants in more northern paddy areas in China (Cheng et al., 1979; NCRG, 1981), early immigrations from April to early May in these areas and their sources are important. Recent trajectory analyses with the simulation model HYSPLIT (Draxler and Hess, 1998) in these areas indicated that possible sources of the early migrations of S. furcifera and N. lugens were
Hainan province, northern and central Vietnam, and southern Laos (Qi et al., 2010a, 2011; Shen et al., 2011b; Wang et al., 2011b; Jiang et al., 2012). The winter-spring rice crop along the coast of central Vietnam is earlier than that in northern Vietnam where the main emigration begins in May (Otuka et al., 2008; Zhai and Chen, 2011), and rice plants in the central region mature in April, which makes them a possible source (Shen et al., 2011b). In addition, SRBSDV in Vietnam in 2009 was distributed in the central regions as well as in the northern delta, suggesting that there was viral dispersion to central Vietnam from southern China, where SRBSDV originated (Hoang et al., 2011). Laos's border with Vietnam is mountainous, providing a possible barrier to migrations heading northeast. Chinese hybrid rice susceptible to S. furcifera is popular in northern Vietnam (Hoang et al., 2011), while sticky rice is popular in Laos. Information on the occurrence of rice planthoppers in spring in southern Laos is limited. Hence, it may be premature to conclude that Laos is a source of the early migration, and further investigation of rice planthoppers' migration and the occurrence of SRBSDV in Laos is necessary. It is likely that both the central and northern parts of Vietnam, as well as southern Hainan province in China, are source areas for the early immigration to Guangdong and Guangxi (Zhai et al., 2011).

It is generally believed that the East Asian populations of S. furcifera and N. lugens overwinter in Vietnam and southern Hainan province, and that in spring they migrate northeastward to eastern China, Japan, and Korea utilizing southwesterly monsoons, then migrate southward back to overwintering areas in autumn (Kisimoto, 1976; Cheng et al., 1979; NCRG, 1981). These tropical rice planthoppers of the Red River Delta in northern Vietnam have been recognized as a main source for the East Asian population, since $N$. lugens shifted from biotype 1 to biotype 2 synchronously in northern Vietnam, China, and Japan from the late 1980s to the beginning of the 1990s (Sogawa, 1992). Now most scientists who study rice insect pests believe the rice planthoppers originally migrated from northern Vietnam and southern Hainan (Zhai et al., 2011). The recent studies on the early migrations in Guangdong and Guangxi presented a modification of the initial belief about migration.

Regarding the epidemic of SRBSDV in China, migrations of S. furcifera in 2009 and 2010 in the northeastern paddy areas between June and July have been investigated as well (Zheng et al., 2011; Zhao et al., 2011a,b; Diao et al., 2012). Immigration sites were located in central Zhejiang, southern Anhui, and southern Jiangxi provinces. Their possible sources were estimated to be Guangdong, eastern Guangxi, southern Jiangxi, and southern Fujian provinces for the Zhejiang case; Jiangxi and Hunan provinces for the Anhui case; and mainly Guangdong province for the Jiangxi case. Additionally, source areas for S. furcifera immigrations in the Kyushu district, western Japan, in June and July, were estimated to be mostly Fujian (Otuka et al., 2005). On the other hand, source areas for S. furcifera immigrants in southern Fujian in April to May from 2007 to 2010 were estimated to be Guangdong and Hainan (Shen et al., 2011a). Possible immigration sources in April to May in western Taiwan were also estimated to be Guangdong, Hainan, and the Philippines (Huang et al., 2010). 


\section{YUNNAN PROVINCE AND INDOCHINA PENINSULA}

Yunnan province is located east of Myanmar, north of Laos and Vietnam, west of Guangxi and Guizhou provinces, and south of Sichuan province (Figure 1). Temperatures in winter and spring in the two-crop rice area in Yunnan are relatively high due to the low latitude, and small numbers of $N$. lugens and S. furcifera can overwinter on rice seedlings and ratoons (Shen, 2010). But immigrants in spring cause most of the major damage (Shen, 2010). Sources of S. furcifera's large immigrations in April to early May in Yunnan were estimated to be mainly Myanmar, and immigrations in mid-May were thought to be from northern Vietnam (Shen et al., 2011c). In Myanmar, new irrigation systems have been developed recently and the winter-spring rice crop in the dry season has increased (Shen, 2010). The change in the farming system in Myanmar seems to be a cause of S. furcifera's immigration to Yunnan.

In the Mekong Delta of Vietnam, in the southeastern end of the Indochina peninsula, an epidemic of N. lugens populations has occurred since the winter-spring rice crop in 2005-2006 (Chien et al., 2007; Hoang et al., 2011), where co-infection of two emerging viruses, Rice grassy stunt virus (RGSV; genus Tenuivirus) and Rice ragged stunt virus (RRSV; genus Oryzavirus)severely damaged more than 485,000 ha of rice production area, resulting in the loss of 828,000 tons of rice (Du et al., 2007; Cabauatan et al., 2009). The co-infection causes yellowing and light stunting of rice leaves (yellowing syndrome; Du et al., 2007). The rate of single infection with RGSV or RRSV, and the rate of co-infection with the two viruses were observed in 90,65 , and $65 \%$ of rice plants collected from 6 provinces in the delta in August 2006, respectively, whereas the rate of $N$. lugens carrying RGSV, RRSV, and both the viruses were 66, 41 and 8\%, respectively (Du et al., 2007). Recently, the two genes encoded by each ambisense segment RNA3 and RNA5 of RGSV isolates from 6 provinces in southern Vietnam (5 provinces in the delta and BinhThuan province, a southeastern province near the delta) were sequenced. The results showed no relationships between the genetic diversity and the geographic distribution of the RGSV isolates, suggesting the viruliferous vector $N$. lugens migrates in southern Vietnam (Ta et al., 2013).

An escape strategy using a monitoring light trap, which shifts the timing of seeding to avoid the peak period of N. lugens immigration from neighboring areas, has been established in the delta to reduce viral infection (Chien et al., 2007, 2012), and campaign efforts to reduce seeding rate, fertilizer rate, and insecticide use have also decreased the density of N. lugens (Huan et al., 2005, 2008). Regarding the pest's resistance to insecticides, however, the $N$. lugens population in the delta is more resistant than a population in northern Vietnam (Matsumura and Sanada-Morimura, 2010). The migration of this insecticide-resistant and viruliferous population is of much interest but is not well known. The monthly mean wind direction from 1979 to 2009 over the delta was investigated recently, and it was found that easterly winds and westerly winds dominated from October to April and from June to September, respectively (Shen, 2010; Zhai et al., 2011). Southerly or southwesterly winds that could carry planthoppers to the north of the peninsula scarcely occurred. This result suggests only a small chance that $N$. lugens's genes flowed from the delta to the northern peninsula.
Migration in Thailand is not well known. Outbreaks of $N$. lugens have occurred in irrigated areas of central Thailand since 2009 (Chaiyawat et al., 2011). A trajectory analysis was applied to light trap data obtained in central Thailand in 2009, revealing three catch peaks: March to early April, the end of July, and November (Shen, 2010). For example, the analysis suggested that emigrants from central Thailand in July could reach Laos, central Vietnam, and Cambodia under seasonal westerly winds.

\section{DISCUSSION}

\section{FLIGHT DURATION OF TROPICAL POPULATIONS}

A number of migration studies of rice planthoppers in northern Vietnam, China, Japan, and Korea have been conducted, but relatively few studies have covered the Indochina peninsula and farther-western rice-producing areas such as Bangladesh and India. The previous migration studies of N. lugens in Thailand and southern Vietnam used flight durations of 12-36 h (Shen, 2010; Zhai et al., 2011). However, flight duration, or the flight distances of most migrating tropical populations, might be shorter than that. In the tropics, shorter migration distances, such as a few to $30 \mathrm{~km}$, have been estimated by radar observations or yellow pan watertrapping in the Philippines (Perfect and Cook, 1987; Riley et al., 1987). The flight duration of $N$. lugens macropters collected in a rice field in the Philippines in a tethered flight experiment peaked at only 3-4 h (Padgham et al., 1987). Moreover, physiological characteristics such as the pre-ovipositional period and starvation tolerance of macropters of tropical $N$. lugens populations are different from those of East Asian N. lugens populations (Wada et al., 2007, 2009). To unveil flight durations or distances in tropical areas of Thailand, southern Vietnam, Cambodia, etc., monitoring with a tow net trap mounted to a tall pole is recommended in combination with the standard migration analysis.

\section{POPULATION DYNAMICS OF S. furcifera AND $\boldsymbol{N}$. lugens}

For S. furcifera and N. lugens in Japan, the paddy-field population is established by the overseas adult immigrants usually in July, soon after the rice transplanting (Kuno, 1968). Then S. furcifera generally produces two generations and the adult macropters of the second generation emigrates from the paddy fields, whereas $N$. lugens multiplies until the third generation and more, resulting in a high growth rate and causing hopperburns (Kuno, 1968). In the tropics, S. furcifera shows the same population dynamics as in Japan, but $N$. lugens generally produce two generations until harvest of rice, and the second generation shows a peak number (Tsurumachi, 1986). Therefore, the vector's emigration timing may differ between in the tropics and in the temperate zone. Since rice seedling and rice plants of young stage are more susceptible to infection of RRSV than those of later stages (Tsurumachi, 1986), the Vietnamese escape strategy to escape N. lugens's mass immigration, hence to avoid early viral infection, is reasonable.

\section{RADAR MONITORING AND RETURN MIGRATION}

Entomological radar has a 40-year history and has provided much information about flying insects at altitudes from the ground (Chapman et al., 2011). Radar observation of rice planthoppers was conducted in the 1980s and early 1990s (Riley et al., 1987, 1991, 1994). Findings on observations, such as vertical group velocity of 


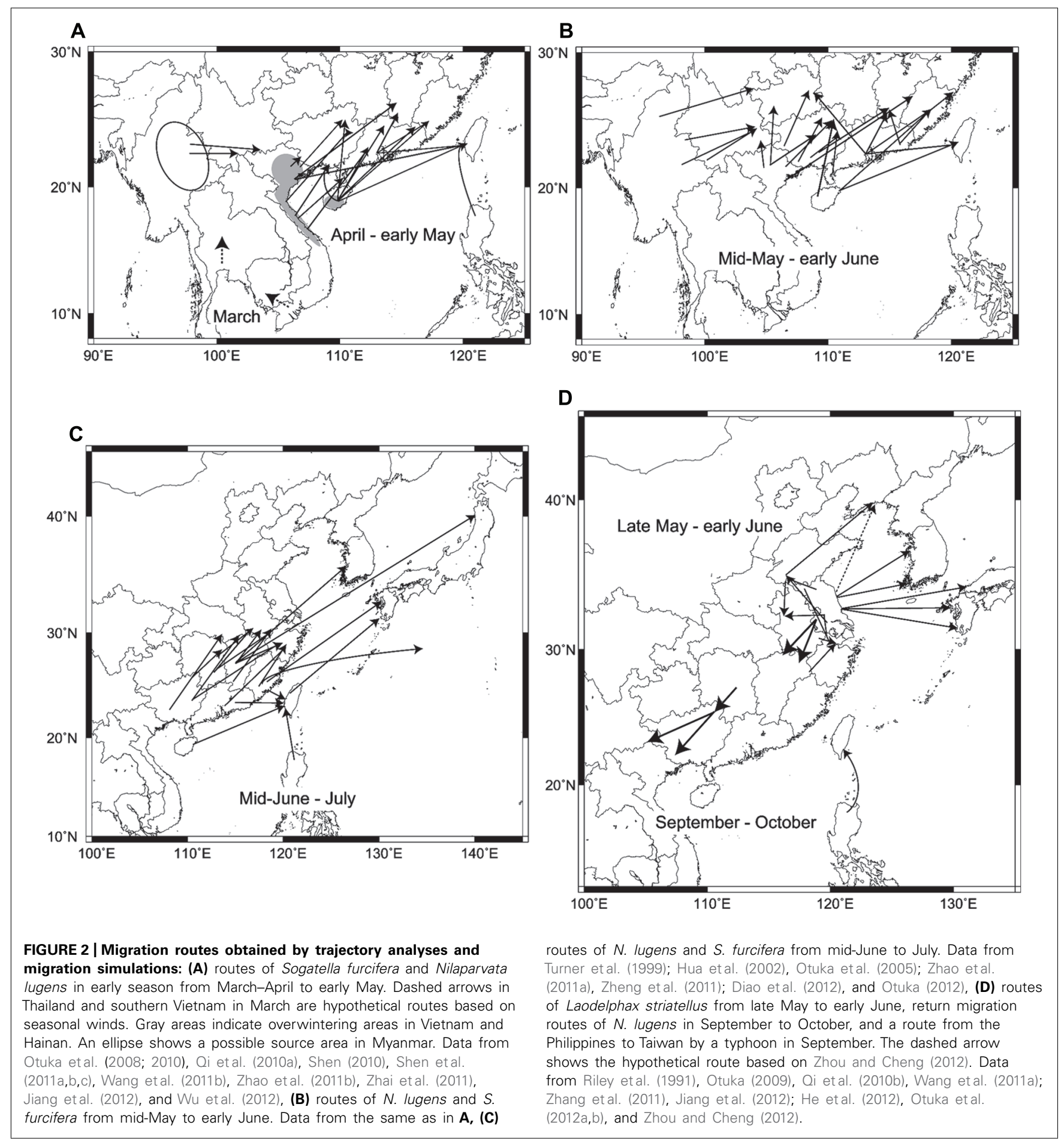

$0.2 \mathrm{~m} / \mathrm{s}$ after takeoff and random heading during flight (Riley et al., 1991), have been used to model a planthopper in a migration simulation model (Furuno et al., 2005). Yang et al. (2008) developed a millimetric scanning radar $(8.8 \mathrm{~mm}$ wavelength, $10 \mathrm{kw}$ peak power, $1.2 \mathrm{~m}$ dish) in China and observed echoes mainly from $N$. lugens and the rice leaf roller, Cnaphalocrocismedinalis (Lepidoptera: Pyralidae). This radar is located in Xing'an, northeastern Guangxi, under the main migration route of rice planthoppers. An

autumn return migration of $N$. lugens was analyzed by the same radar, and dense echo layers were observed at altitudes between 600 and $1,100 \mathrm{~m}$ above ground on the night of October 1 to 2, 2009 (Qi et al., 2010b). The migration direction was toward the southwest. Another study found a sign of collective orientation in N. lugens autumn migration (Jiang and Cheng, 2011), which is known as a dumbbell pattern in the radar echo (Drake and Reynolds, 2012). If collective orientation 
was common in $N$. lugens's migration, the simulation model should be modified to take that into account. Further study is expected.

In summary, the major migration routes of three rice planthopper species in East Asia are illustrated in Figure 2. This figure, which has been made for the first time from many analytical results of trajectory analysis and migration simulation, is much more specific, concrete, and accurate, including the latest situations in East Asia, than a previous summarized figure in Cheng et al. (1979).

Early immigrants of $N$. lugens and S. furcifera in March and April start to arrive from central Vietnam and southern Hainan in rice seedlings or paddy fields of early rice crops in southern Guangxi, Guangdong, and southern Fujian in some years (Figure 2A; Shen et al., 2011a,b; Wang et al., 2011b). During the same period, S. furcifera arrives in Yunnan from Myanmar (Shen etal., 2011c). The dashed arrows on the map of southern Vietnam and Thailand indicate possible migration in March from winter-spring crops, with unknown migration distances. By early May, rice planthoppers reach northern Guangxi, Guangdong, southern Jiangxi, Fujian, and Taiwan from northern Vietnam, Hainan, and already invaded areas in southern Guangxi and Guangdong (Figure 2A; Huang et al., 2010; Qi et al., 2010a; Shen et al., 2011a; Zhao et al., 2011b). The areas of invasion gradually spread northward by early June as the monsoons penetrate northward (Figure 2B). N. lugens and S. furcifera migrate from southern China to paddy fields in the middle and lower reaches of the Yangtze River, western Japan, and Korea from mid-June to July (Figure 2C). Most of the migration routes are slanted in the same direction due to southwesterly low-level jet streams, like the diagonal belt region for early migration described in Otuka et al. (2008). It was shown that overseas migration routes appear to be longer than Chinese routes over land. An estimated flight duration of $58 \mathrm{~h}(2470 \mathrm{~km})$ has been reported for a migration of $S$. furcifera to northern Japan arriving on July 11, 1987 (Figure 2C; Otuka, 2012). A historical migration of S. furcifera and $N$. lugens to South Point $\left(29^{\circ} \mathrm{N}, 135^{\circ} \mathrm{E}\right)$ over the Pacific Ocean on July 16-17, 1967 (Asahina and Turuoka, 1968) was also analyzed, and Fujian was identified as a possible source (52 h, 1770 km; Otuka, 2012). In autumn, N. lugens was observed by entomological radars, and trajectory analyses showed return migrations in a southwest direction (arrows pointing to the southwest in Figure 2D; Riley et al., 1991; Qi et al., 2010b; Jiang et al., 2012). Overseas and Chinese domestic migrations of L. striatellus in late May to early June are shown around Jiangsu in Figure 2D.

\section{REFERENCES}

Asahina, S., and Turuoka, Y. (1968). Records of the insects visited a weather ship located at the Ocean Weather Station "Tango" on the Pacific, II. Kontyu 36, 190-202 (in Japanese).

Cabauatan, P. Q., Cabunagan, R. C., and Choi, I.-R. (2009). "Rice viruses transmitted by the brown planthopper Nilaparvata lugens Stål," in Planthoppers: New Threats to the
Sustainability of Intensive Rice Production Systems in Asia, eds K. L. Heong and B. Hardy (Los Baños: International Rice Research Institute), 357-368.

Chaiyawat, P., Channo, C., and Sriratanasak, W. (2011). BPH Continues to Threaten Thai Rice FarmersHeavy Losses Expected. Available at: http://Ricehoppers.net

Chapman, J., Drake, V. A., and Reynolds, D. R. (2011). Recent

\section{ADDITIONAL INFORMATION TO SOURCE ESTIMATON}

Trajectory analysis and migration simulation are the standard method for finding possible migration sources of rice planthoppers. Moreover, to improve this method's accuracy, different types of additional information were combined or tested, including the data on ovarian development, genetic diversity, insecticide resistance, and trace elements in the insect's body (Mun et al., 1999; Qi et al., 2010a; Otuka et al., 2010, 2012b; Peng et al., 2011; Fu et al., 2012; Matsumoto et al., 2013; Zheng et al., 2013). Ovarian grade in a light trap or paddy field can yield information on differences between emigrants (earliest grade) and immigrants (later grades). Genetic analyses of rice planthoppers' populations in Asia have shown that the internal transcribed spacer (ITS) region of the ribosomal RNA gene of $S$. furcifera populations and the mitochondrial $\operatorname{cox} 1$-trnL2-cox2 regions of $N$. lugens and $S$. furcifera populations did not provide molecular markers with which to discriminate Southeast Asian and East Asian populations (Mun et al., 1999; Fu et al., 2012; Matsumoto et al., 2013). This is because (1) the ITS region of $S$. furcifera is too variable to allow discrimination of local populations, and (2) rice planthoppers that migrate for long distances have well-mixed Asian populations for a long time, and the mitochondrial genetic structures of the populations reflect genetic flow over a longer period (Matsumoto et al., 2013). Thus, there has been no report thus far of a molecular marker for Asian rice planthoppers to help to determine or suggest a migration source.

Meanwhile, the insecticide resistance of both immigrant and local populations can provide good information about differences between two populations, when the two resistance levels are different in estimated source and destination areas. Such was the case when L. striatellus migrated from eastern China to western Japan in 2008 (Otuka et al., 2010), and when N. lugens migrated from the Philippines to Taiwan under typhoon-induced windy conditions in 2010 (Otuka et al., 2012b). In both cases, differences in insecticide resistance between the source and destination populations were utilized to strengthen the identification of migration sources. Recently, trace element content in N. lugens's body was studied to find regional differences. In the study by Peng et al. (2011), concentrations of 23 trace elements ( $\mathrm{Mn}, \mathrm{Mo}, \mathrm{Cd}$, and etc.) in 53 samples from seven regions in southern China were determined; the samples were successfully discriminated by region as a result. In order to apply this idea to a regular migration analysis, a basic database of regional differences in trace element contents in rice planthoppers is necessary. A scientific explanation of how the difference appears based on detailed environmental factors, such as plant, soil, water, and air quality, is also expected.

insights from radar studies of insect flight. Annu. Rev. Entomol. 56, 337-356. doi: 10.1146/annurev-ento120709-144820

Cheng, J.-A., and Zhu, Z.-R. (2006). Analysis on the key factors causing the outbreak of brown planthopper in Yangtze Area, China in 2005. Plant Prot. 32, 1-4 (in Chinese).

Cheng, S.-N., Chen, J.-C., Si, H., Yan, L.-M., Chu, T.-L., Wu, C.-T., et al. (1979). Studies on the migrations of brown planthopper Nilaparvata lugens Stål. Acta Entomol. Sinica 22, 1-21 (in Chinese).

Chien, H. V., Cuong, L. Q., and Thiet, L. V. (2007). "Community level of brown planthopper associated virus diseases management: use of synchronized cropping season and brown planthopper escape strategy," in Proceedings of the International Workshop on Forcasting and Management of Rice Planthoppers in 
East Asia: Their Ecology and Genetics (Kumamoto: National Agricultural Research Center for Kyushu Okinawa Region), 10-19.

Chien, H. V., Cuong, L. Q., Van, D. V., Heong, K. L., Cabunagan, R. C., and Choi, I.-R. (2012). "Management of rice planthopper and related virus diseases in Mekong Delta, South Vietnam," in Proceedings of the NARO International Symposium 2012, New Insight into Insecticide Resistance of Rice Planthoppers and their Associated Virus Diseases (Fukuoka: NARO Kyushu Okinawa Agricultural Research Center), 1516.

Choi, H.-S., Lee, S.-H., Kim, M.-K., Kwak, H.-R., Kim, J.-S., Cho, J.-D., et al. (2010). Occurrence of virus diseases on major crops in 2009. Res. Plant Dis. 16, 1-9 (in Korean). doi: 10.5423/RPD.2010.16.1.001

Diao, Y.-G., Yang, H.-B., Qu, Y.F., Chen, X., Fang, C.-H., Wu, Y., et al. (2012). Analysis on population fluctuation and properties of the white-backed planthopper in Huizhou in 2009. Acta Ecol. Sinica 32, 2872-2882 (in Chinese). doi: $10.5846 /$ stxb201103290403

Drake, V. A., and Reynolds, D. R. (2012). Radar Entomology. Oxfordshire: CABI, 489.

Draxler, R. R., and Hess, G. D. (1998). An overview of the HYSPLIT4 modeling system of trajectories, dispersion, and deposition. Aust. Meteorol. Mag. 47, 295-308.

Du, P. V., Cabunagan, R. C., Cabauatan, P. Q., Choi, H. S., Choi, I. R., Chien, H. V., et al. (2007). Yellowing syndrome of rice: etiology, current status, and future challenges. Omonrice 15, 94-101.

Falk, B. W., and Tsai, J. H. (1998). Biology and molecular biology ofviruses in the genus tenuivirus. Annu. Rev. Phytopathol. 36, 139-163. doi: 10.1146/annurev.phyto.36.1.139

Fu, Q., Matsumoto, Y., Matsumura, M., Hirai, Y., Sato, Y., and Noda, H. (2012). Presence of a short repeat sequence in internal transcribed spacer (ITS) 1 of the rRNA gene of Sogatella furcifera (Hemiptera: Delphacidae) from geographically different population in Asia. Appl. Entomol. Zool. 47, 95-101. doi: 10.1007/s13355-012-0093-y

Furuno, A., Chino, M., Otuka, A., Watanabe, T., Matsumura, M., and Suzuki, Y. (2005). Development of a numerical simulation model for long-range migration of rice planthoppers. Agric. For. Meteorol. 133, 197-209. doi: 10.1016/j.agrformet. 2005.07.018
Gu, K.-L., Wang, Z.-T., Yang, G., Ma, L., and $\mathrm{Xu}$, J.-J. (2005). Cause of epidemic of the small brown planthopper and rice stripe disease and control methods. J. Anhui Agric. Sci. 33, 44 (in Chinese).

He, Y., Zhu, Y.-B., Hou, Y.-Y., Yao, S.T., Lu, Z.-J., Jin, Z.-H., et al. (2012). Fluctuation and migration of spring population of small brown planthopper (Laodelphax striatellus) on wheat in Jiangsu and Zhejiang provinces. Chin. J. Rice Sci. 26, 109-117 (in Chinese).

Hoang, A. T., Zhang, H.-M., Yang, J., Chen, J.-P., Hébrard, E., Zhou, G. H., et al. (2011). Identification, characterization and distribution of Southern rice black-streaked dwarf virus in Vietnam. Plant Dis. 95, 1063-1069. doi: 10.1094/PDIS-07-10-0535

Hua, H.-X., Deng, W.-X., and Li, R.H. (2002). Trajectory analysis on the summer immigrant brown planthoppers Nilaparvata lugens in the middle reaches of the Yangtze River captured by aerial net. Acta Entomol. Sinica 45, 68-74 (in Chinese).

Huan, N. H., Chien, H. V., Quynh, P. V., Tan, P. S., Du, P. V., Escalada, M. M., etal. (2008). Motivating rice farmers in the Mekong Delta to modify pest management and related practices through mass media. Int. J. Pest Manag. 54 339-346. doi: 10.1080/096708708024 03978

Huan, N. H., Thiet, L. V., Chien, H. V., and Heong, K. L. (2005). Farmers participatory evaluation of reducing pesticides, fertilizers and seed rates in rice farming in the Mekong Delta, Vietnam. Crop Prot. 24, 457-464. doi: 10.1016/j.cropro.2004.09.013

Huang, S.-H., Cheng, C.-H., Chen, C.N., Wu, W.-J., and Otuka, A. (2010). Estimating the immigration source of rice planthoppers, Nilaparvata lugens (Stål) and Sogatella furcifera (Horváth) (Homoptera: Delphacidae), in Taiwan. Appl. Entomol. Zool. 45, 521-531. doi: 10.1303/aez.2010.521

Iizuka, K. (1989). Trend of Rice stripe virus viruliferous rate in northern Kanto district and pest management. Agric. Hortic. 64, 965-970 (in Japanese).

Jeong, T.-W., Kim, B.-R., Han, G. S., Kang, D.-W., Jeong, I.-Y., Lim, H.-S., et al. (2012). Evaluation of pesticide treatment for control of Rice stripe virus after mass migration of small brown planthoppers. Res. Plant Dis. 18, 245-249 (in Korean). doi: 10.5423/RPD.2012.18.3.245

Jiang, C.-X., and Cheng, D.-F. (2011). Radar observations of the migration of Nilaparvata lugens S. (Delphacidae) in southern China. Phytopathology 101, S83.

Jiang, C.-X., Wu, J.-J., Qi, H.-H., Zhang, Y.-H., and Cheng, D.-F. (2012). Occurrence dynamic and trajectory analysis of Nilaparvata lugens in Xing'an, Guangxi. Acta Phytophylacica Sinica 39, 523-530 (in Chinese).

Jonson, M. G., Choi, H.-S., Kim, J.S., Choi, I.-R., and Kim, K.-H (2009). Complete genome sequence of the RNAs3 and 4 segments of Rice stripe virus isolates in Korea and their phylogenetic relationships with Japan and China isolates. Plant Pathol. J. 25, 142-150. doi: 10.5423/PPJ.2009.25.2.142

Kim, J.-S. (2009). "Forecasting and occurrence of SBPH and RSV in Korea," in Proceedings of the APEC Workshop on the Epidemics of Migra tory Insect Pests and Associated Virus Diseases in Rice and their Impact on Food Security in APEC Member Economies (Seoul: Rural Development Administration), 87-107.

Kim, J.-S., Lee, S.-H., Choi, H.-S., Kim, M.-K., Kwak, H.-R., Cho, J.D., et al. (2009). Occurrence of Virus Diseases on Major Crops in 2008. Res. Plant Dis. 15, 1-7 (in Korean). doi: 10.5423/RPD.2009.15.1.001

Kiritani, K. (1983). "Changes in cropping practices and the incidence of hopper-borne diseases of rice in Japan," in Plant Virus Epidemiology, eds R. T. Plumb and J. M. Thresh (Oxford: Blackwell Scientific Publications), 239-247.

Kisimoto, R. (1976). Synoptic weather conditions including long-distance immigration of planthoppers, Sogatella furcifera Horváth and Nilaparvata lugens Stål. Ecol. Entomol. 1, 95-109. doi: 10.1111/j.13652311.1976.tb01210.x

Kuno, E. (1968). Studies on the population dynamics of rice leafhoppers in a paddy field. Bull. Kyushu Agric. Exp. Stn. 14, 131-246 (in Japanese).

Lan, Y., Zhou, T., Fan, Y.-J., and Zhou, Y.-J. (2012). Advances in rice resistance to two virus diseases carried by small brown planthopper. Jiangsu J. Agric. Sci. 28, 1480-1486 (in Chinese).

Lee, G.-S., Kim, C.-S., and Choi, H.-S. (2012). "Recent SBPH's overseas migration and RSV occurrence in Korea," in Proceedings of the NARO International Symposium 2012, New Insight into Insecticide Resistance of Rice Planthoppers and their Associated Virus Disease (Fukuoka: NARO Kyushu Okinawa Agricultural Research Center), 2.
Liu, X.-D., Zhai, B.-P., and Hu., Z.-Q. (2007). Effects of rice type and temperature on the population of the rice small brown planthopper, Laodelphax striatellus. Chin. Bull. Entomol. 44, 348-352 (in Chinese).

Ma, C.-Y., Gao, C. F., Wei, H.-J., and Shen, J.-L. (2007). Resistance and susceptibility to several groups of insecticides in the small brown planthopper, Laodelphax striatellus (Homoptera: Delphacidae). Chin. J. Rice Res. 21, 555-558 (in Chinese).

MAFF, (2009). Statistics of Occurrence Area of Diseases and Insect Pests. Tokyo: Ministry of Agriculture, Forestry and Fisheries (in Japanese).

Matsumoto, Y., Matsumura, M., Sanada-Morimura, S., Hirai, Y., Sato, Y., and Noda, H. (2013). Mitochondrial cox sequences of Nilaparvata lugens and Sogatella furcifera (Hemiptera: Delphacidae): low specificity among Asian planthopper populations. Bull. Entomol. Res. 103, 382-392. doi: $10.1017 / S 000748531200082 \mathrm{X}$

Matsumura, M., and Sakai, J. (2011). Occurrence of new disease caused by Southern rice black-streaked dwarf virus transmitted by the whitebacked planthopper. Plant Prot. 65, 244-246 (in Japanese).

Matsumura, M., and SanadaMorimura, S. (2010). Recent status of insecticide resistance in Asian rice planthoppers. JARQ 44, 225-230. doi: 10.6090/jarq.44.225

Matsumura, M., Takeuchi, H., Satoh, M., Sanada-Morimura, S., Otuka, A., Watanabe, T., et al. (2008). Speciesspecific insecticide resistance to imidacloprid and fipronil in the rice planthoppers Nilaparvata lugens and Sogatella furcifera in East and Southeast Asia. Pest Manag. Sci. 64, 11151121. doi: 10.1002/ps.1641

Matthews, R. E. F. (1991). Plant Virology, 3rd Edn. San Diego: Academic Press, 835.

Mun, J. H., Song, Y. H., Heong, K. L., and Roderick, G. K. (1999). Genetic variation among Asian populations of rice planthoppers, Nilaparvata lugens and Sogatella furcifera (Hemiptera: Delphacidae): mitochondrial DNA sequences. Bull. Entomol. Res. 89, 245-253. doi: 10.1017/S000748539900036X

Nakagawa, K., and Mizobe, S. (2010). Numerous occurrence factor of small brown planthopper and the rice stripe disease in Yamaguchi prefecture after 2008. Bull. Yamaguchi Agric. For. Gen. Technol. Cent. Exp. Stn. 1, 24-30 (in Japanese).

National Coordinated Research Group for White Back Planthoppers 
(NCRG) NCRG (1981). Studies on the migration of white back planthoppers. Sci. Agric. Sinica 5, 25-31 (in Chinese).

Ohtsu, R., Sakai, Y., and Eto, H. (2009). Occurrence of rice stripe disease in Nagasaki prefecture in 2008. Kyushu Plant Prot. Res. 55, 173 (in Japanese).

Otuka, A. (2009). "Migration analysis of the small brown planthopper, Laodelphax striatellus, in western Japan and Korea," in Proceedings of the APEC Workshop on the Epidemics of Migratory Insect Pests and Associated Virus Diseases in Rice and their Impact on Food Security in APEC Member Economies (Seoul: Rural Development Administration), 145-157.

Otuka, A. (2012). Rice planthopper as an overseas traveler. Kagaku 82, 901-905 (in Japanese)

Otuka, A., Zhou, Y., Lee, G.-S., Matsumura, M., Zhu, Y., Park, H.-H., et al. (2012a). Prediction of overseas migration of the small brown planthopper, Laodelphax striatellus (Hemiptera: Delphcidae) in East Asia. Appl. Entomol. Zool. 47, 379 388. doi: 10.1007/s13355-012-0130-x Otuka, A., Huang, S.-H., SanadaMorimura, S., and Matsumura, M. (2012b). Migration analysis of Nilaparvata lugens (Hemiptera: Delphacidae) from the Philippines to Taiwan under typhoon-induced windy conditions. Appl. Entomol. Zool. 47, 263-271. doi: 10.1007/s13355-012-0118-6

Otuka, A., Matsumura, M., SanadaMorimura, S., Takeuchi, H., Watanabe, T., Ohtsu, R., etal. (2010). The 2008 overseas mass migration of the small brown planthopper, Laodelphax striatellus, and subsequent outbreak of rice stripe disease in western Japan. Appl. Entomol. Zool. 45, 259-266. doi: 10.1303/aez.2010.259

Otuka, A., Matsumura, M., Watanabe, T., and Dinh, V. T. (2008). A migration analysis for rice planthoppers, Sogatella furcifera (Horváth) and Nilaparvata lugens (Stål) (Homoptera: Delphacidae), emigrating from northern Vietnam from April to May. Appl. Entomol. Zool. 45, 259-266. doi: 10.1303/aez.2010.259

Otuka, A., Watanabe, T., Suzuki, Y., and Matsumura, M. (2005). Estimation of the migration source for the white-backed planthopper, Sogatella furcifera (Horváth) (Homoptera: Delphacidae) immigrating into Kyushu in June. Jpn. J. Appl. Entomol. Zool. 49, 187-194 (in Japanese). doi: 10.1303/jjaez.2005.187

Padgham, D. E., Perfect, T. J., and Cook, A. G. (1987). Flight behaviour in the brown planthopper, Nilaparvata lugens (Stål) (Homoptera: Delphacidae). Insect Sci. Appl. 8, 71-75.

Peng, Q., Tang, Q.-Y., Wu, J.-L., Miao, Q.-L., and Cheng, J.-A. (2011). Determining the geographic origin of the brown planthopper, Nilaparvata lugens, using trace element content. Insect Sci. 19, 21-29. doi: 10.1111/j.1744-7917.2011.01438.x

Perfect, T. J., and Cook, A. G. (1987). Dispersal patterns of the rice brown planthopper, Nilaparvata lugens (Stål), in a tropical ricegrowing system and their implications for crop protection. J. Plant Prot. Tropics 4, 121-127.

Qi, G.-J., Lu, F., Hu, G., Wang, F.Y., Cheng, X.-N., Shen, H.-M., et al. (2010a). Dynamics and population analysis of the brown planthopper Nilaparvata lugens (Stål) in the early rice field in Guangxi Municipality, in 2007. Acta Ecol. Sinica 30, 462-472 (in Chinese).

Qi, H.-H., Zhang, Y.-H., Cheng, D.F., Han, E.-B., and Sun, J.-R (2010b). Radar observation and trajectory analysis on the autumn return migration of the brown planthopper, Nilaparvata lugens (Homoptera: Delphacidae) in 2009 in China. Acta Entomol. Sinica 53, 1256-1264 (in Chinese).

Qi, H.-H., Zhang, Y.-H., Jiang, C.-X., Sun, M.-Y., Yang, X-L., and Cheng, D.-F. (2011). Analysis of the source areas of the early immigration of white-backed planthopper in northeast Guangxi of China. Sci. Agric. Sinica 44, 3333-3342 (in Chinese).

Riley, J. R., Cheng, X.-N., Zhang, X.X., Reynolds, D. R., Xu, G.-M., Smith, A. D., et al. (1991). The longdistance migration of Nilaparvata lugens (Stål) (Delphacidae) in China: radar observations of mass return flight in autumn. Ecol. Entomol. 16, 471-489. doi: 10.1111/j.13652311.1991.tb00240.x

Riley, J. R., Reynolds, D. R., and Farrow, R. A. (1987). The migration of Nilaparvata lugens (Stål) (Delphacidae) and other Hemiptera associated with rice during the dry season in the Philippines: a study using radar, visual observations, aerial netting and ground trapping. Bull. Entomol. Res. 77, 145-169. doi: $10.1017 /$ S0007485300011627

Riley, J. R., Reynolds, D. R., Smith, A. D., Rosenberg, L. J., Cheng, X.-N., Zhang, X.-X., et al. (1994). Observations on the autumn migration of Nilaparvata lugens (Homoptera: Delphacidae) and other pests in east central China. Bull. Entomol. Res. 84, 389-402. doi: $10.1017 / \mathrm{S} 0007485300032521$
Sakai, J., Onuki, M., Matsukura, K., Otuka, A., Sanada-Morimura, S. Zhou, Y., et al. (2011). Rice stripe virus population in Kyushu district is closely related to that of eastern China in a phylogenetic analysis. Kyushu Plant Prot. Res. 57, 7-13 (in Japanese). doi: 10.4241/kyubyochu. 57.7

Sanada-Morimura, S., Sakumoto, S., Ohtsu, R., Otuka, A., Huang, S.-H., Dinh, V. T., et al. (2011). Current status of insecticide resistance in the small brown planthopper, Laodelphax striatellus, in Japan, Taiwan, and Vietnam. Appl. Entomol. Zool. 46, 6573. doi: 10.1007/s13355-010-0009-7

Seino, H., Shiotsuki, Y., Oya, S., and Hirai, Y. (1987). Prediction of of long-distance migration of rice planthoppers to northern Kyushu considering low-level jet stream. J. Agric. Meteorol. 43, 203-208. doi: 10.2480/agrmet.43.203

Shen, H.-M. (2010). The Study on Oversea Source Area of Nilaparvato lugens (Stål) and Sogatella furcifera (Horváth) in China. Ph.D. thesis, Nanjing Agricultural University, China (in Chinese).

Shen, H.-M., Kong, L.-P., Zhang, S.-H., Zhang, X.-X., and Zhai, B.-P. (2011a). Analysis of the source areas of the early immigration of the white-backed planthopper, Sogatella furcifera (Horváth) (Homoptera: Delphacidae) in Fujian province, China. Acta Entomol. Sinica 54, 701-713. (In Chinese)

Shen, H.-M., Chen, X., Hu, G., Cheng, X.-N., Zhang, X.-X., and Zhai, B.-P. (2011b). Analysis on the early immigration of rice planthoppers in southern Guangxi. Chin. J. Appl. Entomol. $48,1268-1277$ (in Chinese).

Shen, H.-M., Lv, J.-P., Zhou, J.-Y., Zhang, X.-X., Cheng, X.-N., and Zhai, B.-P. (2011c). Source areas and landing mechanism of early immigration of white-backed planthoppers Sogatella furcifera (Horváth) in Yunnan 2009. Acta Ecol. Sinica 31, 4350-4364 (in Chinese).

Sogawa, K. (1992). A change in biotype property of brown planthopper populations immigrating into Japan and their probable source areas. Proc Assoc. Plant Prot. Kyushu 38, 63-68. doi: 10.4241/kyubyochu.38.63

Sogawa, K. (2005). Epidemic of rice stripe disease in Jiangsu province, China. Nogyo Gijutsu 60, 405-409 (in Japanese).

Syobu, S., Otuka, A., and Matsumura, M. (2011). Trap catches of the small brown planthopper, Laodelphax striatellus (Fallén) (Hemiptera: Delphacidae), in northern Kyushu district, Japan in relation to weather conditions. Appl. Entomol. Zool. 46, 41-50. doi: 10.1007/s13355-0100005-y

Ta, H.-A., Nguyen, D.-P., Causse, S., Nguyen, T.-D., Ngo, V.-V., and Hébrard, E. (2013). Molecular diversity of Rice grassy stunt virus in Vietnam. Virus Genes 46, 383-386. doi: 10.1007/s11262-012-0845-3

Tsurumachi, M. (1986). "Population growth pattern of the brown planthopper in Thailand," in Proceedings of the International Symposium on Virus Diseases of Rice and Leguminous Crops in the Tropics, Tropical Agriculture Research Series No. 19 (Tsukuba: Tropical Agriculture Research Center), 209-219.

Turner, R., Song, Y. H., and Uhm, K.-B. (1999). Numerical model simulations of brown planthopper Nilaparvata lugens and white-backed planthopper Sogatella furcifera (Hemiptera: Delphacidae) migration. Bull. Entomol. Res. 89, 557-568. doi: 10.1017/S0007485399000711

Wada, T., Ito, K., Takahashi, A., and Tang, J. (2007). Variation of preovipositional period in the brown planhopper, Nilaparvata lugens, collected in tropical, subtropical and temperate Asia. J. Appl. Entomol. 131, 698-703. doi: 10.1111/j.14390418.2007.01185.x

Wada, T., Ito, K., Takahashi, A., and Tang, J. (2009). Starvation tolerance of macropters brown planthopper, Nilaparvata lugens, from temperate, subtropical, and tropical populations in East and South-East Asia. Entomol. Exp. Appl. 130, 7380. doi: 10.1111/j.1570-7458.2008. 00796.x

Wan, L., Han, C., Xu, Y.-B., Cai, G.-C., Sun, Y.-W., Hu, X.-Y., et al. (2011). Migration and dispersal of the small brown planthopper Laodelphax striatellus (Fallén) in the Jianghuai region: case studies in Fengtai, Anhui province in spring of 2009 and 2010. Chin. J. Appl. Entomol. 48, 1288-1297 (in Chinese).

Wang, H.-D., Chen, J.-P., Wang, A.G., Jiang, X.-H., and Adams, M. J. (2009). Studies on the epidemiology and yield losses from rice black-streaked dwarf disease in a recent epidemic in Zhejiang province, China. Plant Pathol. 58, 815825. doi: 10.1111/j.1365-3059.2009. 02091.x

Wang, H.-D., Chen, J.-P., Zhang, H.M., Sun, X.-L., Zhu, J.-L., Wang, A.-G., et al. (2008). Recent rice stripe virus epidemics in Zhejiang province, China, and experiments on sowing date, disease-yield loss relationships, 
and seedling susceptibility. Plant Dis. 92, 1190-1196. doi: 10.1094/PDIS92-8-1190

Wang, L., Han, C., Xu, Y.-B., Cai, G.-C., Sun, Y.-W., Hu, X.-Y., et al. (2011a). Migration and dispersal of the small brown planthopper Laodelphax striatellus (Fallén) in the Jianghuai region: case studies in Fengtai, Anhui province in spring of 2009 and 2010. Chin. J. Appl. Entomol. 48, 1288-1297 (in Chinese).

Wang, Z., Qi, G.-J., Lv, L.-H., Hu, Q., and Yuan, W.-X. (2011b). Analysis of the source areas of early immigrant white-backed planthopper Sogatella furcifera (Horváth) in Guangdong province. Chin. J. Appl. Entomol. 48, 1253-1259 (in Chinese).

Wei, T.-Y., Yang, J.-G., Liao, F.-L., Gao, F.-L., Lu, L.-M., Zhang, X.T., et al. (2009). Genetic diversity and population structure of rice stripe virus in China. J. Gen. Virol. 90, 1025-1034. doi: 10.1099/vir.0.006 858-0

Wu, J.-J., Jiang, C.-X., Zhang, Y.H., Qi, H.-H., Li, Q., and Cheng, D.-F. (2012). Occurrence dynamics and trajectory analysis of the white-backed planthopper, Sogatella furcifera, Xing'an of Guangxi Municipality in 2011. Plant Prot. 38, 51-57 (in Chinese).

Wu, W.-Q., Guo, X.-G., Zhang, H.-M., Yang, J., Lv, M.-F., and Chen, J.-P. (2013). Simultaneous detection and survey of three rice viruses in China. Plant Dis. doi: 10.1094/PDIS-02-120207-RE

Xi, B.-G., Zhang, Q., Xu, D.-J., Wang, Y.-H., and Zhou, W.-J. (2005). Preliminary study on the epidemic and the cause of rice stripe blight in hill area along Yangtze River. J. Anhui Agric. Sci. 33, 589-590 (in Chinese).

Xian, Y., Gu, A.-D., Ma, Y., and Zhu, G.-L. (2005). Cause of epidemic of rice stripe disease and integrated pest management. J.
Anhui Agric. Sci. 33, 408 (in Chinese).

Yang, R.-M., Diao, C.-Y., and Zhu, Y.-Q. (2002). Factors for swelling up of rice stripe virus and its control measures in Jinagsu province. Plant Prot. Tech. Ext. 22, 9-12 (in Chinese).

Yang, X.-L., Chen, L., Cheng, D.-F., and Sun, J.-R. (2008). Primary application of millimetric scanning radar to tracking high-flying insects in southern China. Plant Prot. 34, 31-36 (in Chinese).

Zhai, B.-P., and Chen, X. (2011). "Migration of white-backed planthopper and the epidemic of Southern rice black-streaked dwarf virus," in Proceedings of the International Workshop on the Collaboration Network for Control of Migratory Rice Planthoppers and Associated Virus Diseases of Rice in Asia (Suwon: National Academy of Agricultural Science), 275-303.

Zhai, B.-P., Zhou, G.-H., Tao, X.-R., Chen, X., and Shen, H.-M. (2011). Macroscopic patterns and microscopic mechanisms of the outbreak of rice planhoppers and epidemic SRBSDV. Chin. J. Appl. Entomol. 48, 480-487 (in Chinese).

Zhang, H.-Y., Diao, Y.-G., Yang, H.B., Zhao, Y., Zhang, X.-X., and Zhai, B.-P. (2011). Population dynamics and migration characteristics of the small brown planthopper in spring in Jining, Shandong province. Chin. J. Appl. Entomol. 48, 1298-1308 (in Chinese).

Zhao, Y., Wu, C.-X., Zhu, X.-D., Jiang, X.-H., Zhang, X.-X., and Zhai, B.-P. (2011a). Tracking the source regions of Southern rice black-streaked dwarf virus (SRBSDV) occurred in Wuyi county, Zhejiang province, China in 2009, transmitted by Sogatella furcifera (Horváth) (Homoptera: Delphacidae). Acta Entomol. Sinica 54, 949-959 (in Chinese).

Zhao, Y., Zhang, X.-X., and Zhai, B.P. (2011b). Identifying the source regions of Southern rice blackstreaked dwarf virus transmitted by Sogatella furcifera (Horváth) in Shangyou, Jinagxi province. Chin. J. Appl. Entomol. 48, 1321-1334 (in Chinese).

Zheng, D.-B., Hu, G., Yang, F., Du, X.-D., Yang, H.-B., Zhang, G., et al. (2013). Ovarian development status and population characteristics of Sogatella furcifera (Horváth) and Nilaparvata lugens (Stål): implications for pest forecasting. J. Appl. Entomol. doi: 10.1111/jen. 12067

Zheng, D.-B., Yang, F., Zhao, Y., Xu, J.-F., Wu, C.-L., Zhang, X.-X., et al. (2011) Formation of white-backed planthopper Sogatella furcifera (Horváth) populations: Case studies in Qianshan, Anhui province 2009. Chin. J. Appl. Entomol. 48, 1242-1252 (in Chinese).

Zhou, G.-H., Wen, J.-J., Cai, D.J., Li, P., Xu, D.-L., and Zhang, S.-G. (2008). Southern rice blackstreaked dwarf virus: a new proposed Fijivirus species in the family Reoviridae. Chin. Sci. Bull. 53, 36773685. doi: 10.1007/s11434-0080467-2

Zhou, G.-H., Xu, D.-L., Xu, D. G., and Zhang, M.-X. (2013). Southern rice black-streaked dwarf virus: a white-backed planthopper transmitted fijivirus threatening rice production in Asia. Front. Microbiol. 4:270. doi: 10.3389/fmicb.2013. 00270

Zhou, G.-H., Zhang, S.-G., Zou, S.-F., Xu, Z.-W., and Zhou, Z.-Q. (2010). Occurrence and damage analysis of a new rice dwarf disease caused by Southern rice black-streaked dwarf virus. Plant Prot. 36, 144-146 (in Chinese).

Zhou, Y.-J. (2010). Rice Stripe Virus Disease. Nanjing: Phoenix Science Press, 220 (in Chinese).

Zhou, Y.-J., and Cheng, Z.-B. (2012).

"Occurrence of Rice stripe virus and a proof for long-distance immigration of SBPH with RSV in China," in Proceedings of the NARO International Symposium 2012, Newinsight into Insecticide Resistance of Rice Planthoppers and their Associated Virus Diseases (Fukuoka: NARO Kyushu Okinawa Agricultural Research Center Fukuoka), 6.

Zhu, Y.-Q. (2012). “Occurrence of RSV and RBSDV and their management in Jiangsu province, P. R. China," in Proceedings of the NARO International Symposium 2012, New Insight into Insecticide Resistance of Rice Planthoppers and their Associated Virus Diseases (Fukuoka: NARO Kyushu Okinawa Agricultural Research Center), 1.

Conflict of Interest Statement: The author declares that the research was conducted in the absence of any commercial or financial relationships that could be construed as a potential conflict of interest.

Received: 10 August 2013; accepted: 27 September 2013; published online: 28 October 2013.

Citation: Otuka A (2013) Migration of rice planthoppers and their vectored re-emerging and novel rice viruses in East Asia. Front. Microbiol. 4:309. doi: 10.3389/fmicb.2013.00309

This article was submitted to Virology, a section of the journal Frontiers in Microbiology.

Copyright (c) 2013 Otuka. This is an openaccess article distributed under the terms of the Creative Commons Attribution License (CC BY). The use, distribution or reproduction in other forums is permitted, provided the original author(s) or licensor are credited and that the original publication in this journal is cited, in accordance with accepted academic practice. No use, distribution or reproduction is permitted which does not comply with these terms. 